\title{
Some functions of collateral behavior '
}

DIANE D. EDWARDS AND GAIL A. DART ${ }^{2}$ UNIVERSITY OF MISSOURI AT KANSAS CITY
A systematic replication of Bruner \& Revesky (1961) demonstrated that disruption of collateral behavior had differential effects on the maintenance of a reinforced operant. These effects were a function of whether the organism was engaged in acquiring or maintaining the terminal performance.

The variables which control both acquisition and maintenance of sequences of behavior have not yet been isolated. Reinforcement of low rate responding is often found to produce concurrent superstitions (Catania, 1966) in which collateral behaviors appear during the intervals between reinforced operants. Wilson \& Keller (1953), Bruner \& Revesky (1961), Hodos, Ross, \& Brady (1962), Laties \& Weiss (1962), Segal \& Holloway (1963), and Laties, Weiss, Clark, \& Reynolds (1965) all report the occurrence of collateral behaviors. In 1965, Laties et al attempted a systematic manipulation of the collateral behavior in order to assess its function in the maintenance of DRL performance (one in which reinforcers are delivered only if a prescribed time has intervened between responses). They reported that collateral responses (mouth-tail contacts) functioned to maintain the efficiency of the reinforced operant.

Bruner and Revesky found that humans engaged in behaviors on three available telegraph keys during the time between response-contingent points delivered via a DRL schedule on a fourth key. They concluded "thus, these unsolicited, 'impromptu' responses become a functional chain of conditioned reinforcers which successfully maintain DRL performance" (p. 350).

However, the mere presence of responding on the irrelevant keys is not sufficient evidence for a description of these responses in terms of their function. The purpose of the present study was to provide a systematic replication of the Bruner and Revesky study by directly manipulating unsolicited responses while simultaneously assessing the effect on DRL performance. The results of such a replication would serve to assess the role of adventitiously acquired responses in the maintenance of behavior.

Method

Nine adults, 20-25 years of age, served as experimental Ss. There were three men and six women.

The experiment was executed in a room equipped with a one-way mirror. The Ss were seated in front of a table with their right side to the mirror. The table top was supplied with four telegraph keys spaced 5 in. apart, lights in front of each key, which provided visual feedback for key presses, and a counter. A red light was placed directly in front of the key on which points were available and a counter provided the number of points obtained during a session. All key presses and points delivered were recorded on a polygraph event recorder, and the key presses for which points were available were recorded on a cumulative recorder. All programming and recording apparatuses were located in a separate room.

Each $\mathrm{S}$ was brought into the experimental room and instructed as follows:

"You may receive points by pressing these keys. You may press any of these keys you wish. At the end of the session you will be given a penny for every point that you have earned on the counter."

The experiment included the following phases: In the first, and in all subsequent phases, each $\mathrm{S}$ was on a $10 \mathrm{sec}$ DRL schedule. All four keys were available in this phase.

When responding was stable, the key pressed most frequently was removed, then the two keys pressed most frequently, and finally all but the DRL key were removed. All keys were then replaced, and baseline, contingency control (points presented noncontingently every $10 \mathrm{sec}$ ) and extinction were assessed.

Results

In the present experimental situation, the production of response sequences was dependent upon the partic-
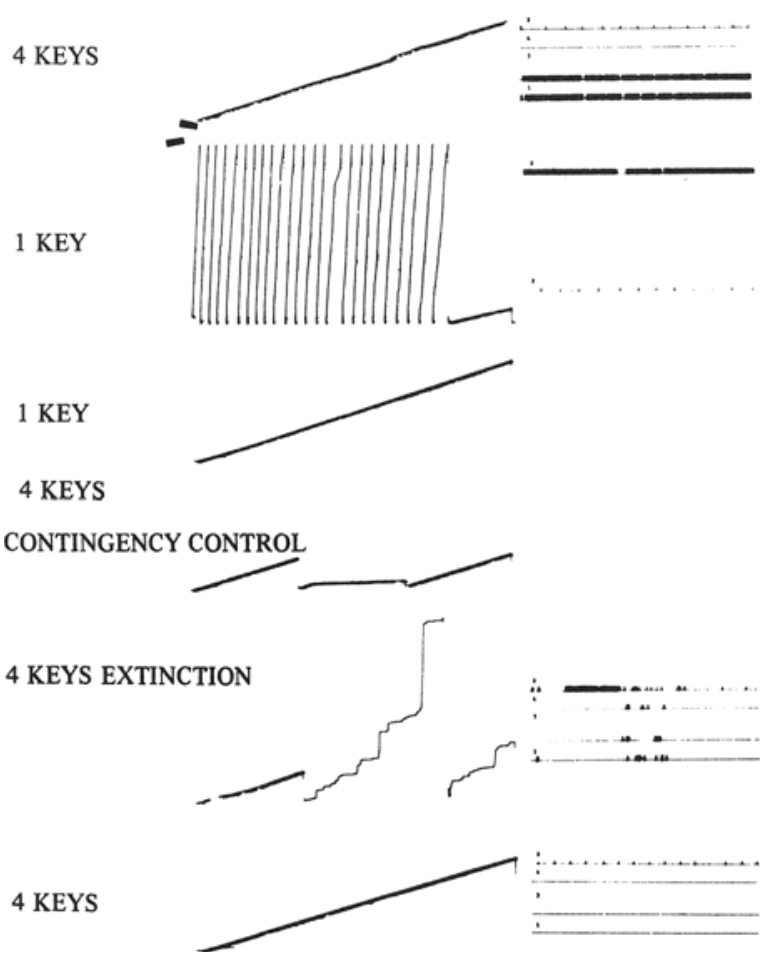

Fig. 1. Selected cumulative records and polygraph recordings of a human $\mathbf{S}$ using collateral behavior. 
ular S. Since it was possible to obtain maximum number of points without ever using the noncontingent keys, four out of the nine Ss never engaged in response sequences.

Figure 1 presents both cumulative records and polygraph recordings from one $S$ throughout the experiment. During the initial phase of the study, response sequences were present on the first and third noncontingent keys while DRL performance was successfully acquired and maintained. When all but the DRL key were removed, the spaced responding was dismupted and sequences were produced on the key. However, by the end of that session, DRL performance was present, and high rate responding was eliminated. This was typical of the next complete session. During the contingency control, responding ceased and during extinction, rates were high. Finally, when all four keys were again made available, no response sequences occurred.

Figure 2 represents a $S$ whose acquisition of DRL performance was slow compared with other Ss. Responses on the noncontingent keys were high, ranging from 30 to 150 responses a min. As long as there was

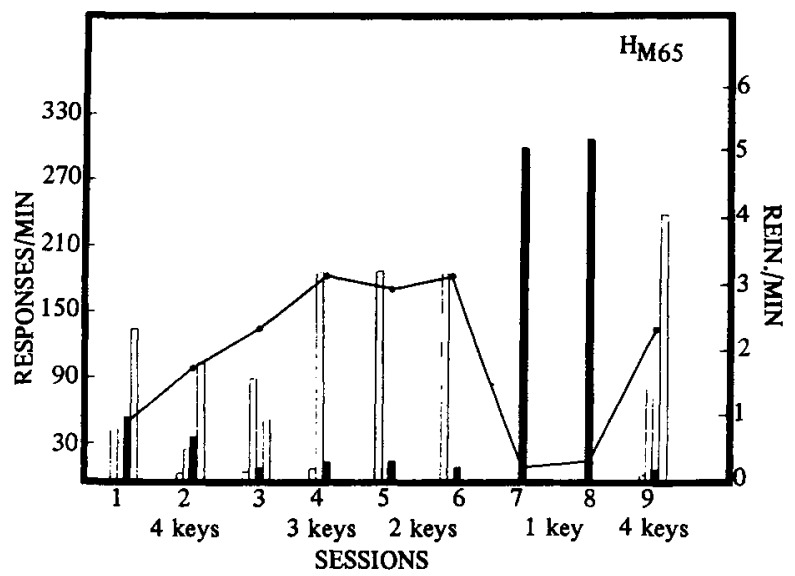

Fig. 2. Responses per min and reinforcers per min plotted as a function of No. of keys available for collateral behavior. at least one noncontingent key available, DRL performance was efficient, as can be seen up to Session 6 . However, when all but the DRL key were removed, relatively little spaced responding occurred in spite of the fact that few points were obtained. Response sequences were again apparent when all keys were replaced.

\section{Discussion}

With one exception, all Ss who used an overt sequence of responses to acquire the terminal performance on the DRL schedule showed that their terminal performance was no longer dependent upon the production of the entire sequence of responses. Acquisition is defined as the ability to space responding on the DRL key, while maintenance is defined as the persistence of that behavior upon the removal of the noncontingent keys.

The data presented here suggest that the different functions which collateral behaviors fulful in the production of terminal behaviors may be due to whether the organism is still in a stage of acquisition or whether the behavior is in a state of maintenance.

\section{References}

BRUNER, A., \& REVESKY, S. H. Collateral behavior in humans. J. exp. Anal. Behav., 1961, 4, 349-350.

CATANIA, A. C. Concurrent operants. In W. K. Honig (Ed.), Operant Behavior. New York: Appleton-Century-Crofts, 1966. Pp. 213-270.

HODOS, W., ROSS, G. S., \& BRADY, J. V. Complex response patterns during temporally spaced responding. J. exp. Anal. Behav., 1962, 5, 473-479.

LATIES, V. G., \& WEISS, B. Effects of alcohol on timing behavior. $J$. exp. Anal Behav., 1958, 1, 359-364.

LATIES, V. G., WEISS, B., CLARK, R. L., \& REYNOLDS, M. D. Overt "mediating" behavior during temporally spaced responding. J. exp. Anal. Behav., 1965, 8, 107-116.

SEGAL, E. F., \& HOLLOWAY, S. M. Timing behavior in rats with water drinking as a mediator. Science, 1963, 140, 888-889.

WLSON, M. P., \& KELLER, F. S. On the selective reinforcement of spaced responses. J. comp. physiol. Psychol, 1953, 46, 190-193.

\section{Notes}

1. This research was supported in part by a grant from Graduate School, UMKC to first author.

2. Now at University of Maryland. 